ARTIGOS

\section{CONCEITO SOBRE ESTRATÉGIA: A PERCEPÇÃO DE PROFISSIONAIS VERSUS A VISÃO DE AUTORES CONSAGRADOS}

\section{RESUMO}

O tema desenvolvido neste trabalho tem como eixo central a comparação entre o conhecimento tácito e o teórico acerca do que seja estratégia, a fim de observar como se dá a evolução ou mudança de pensamento do pesquisado com relação ao que expõem alguns autores consagrados. Para tanto, alunos da disciplina Estratégia Empresarial, do Mestrado Profissional em Administração de uma universidade pública do Ceará foram submetidos, no início da disciplina, a uma avaliação composta por uma questão aberta, por meio da qual deveriam expor suas opiniões a respeito do significado do conceito de estratégia. Ao final da referida disciplina, outra avaliação foi aplicada, contendo a mesma questão aberta, com o intuito de avaliar o grau de conhecimento adquirido sobre os conceitos de estratégia após a apresentação e discussão de textos referentes ao tema. De posse do material coletado, procedeu-se a uma análise de conteúdo, apoiada pelo software Sphinx Léxica-V5, a fim de se obterem dados que auxiliassem na interpretação e compreensão das opiniões formuladas pelos alunos. A partir desses dados, pode-se estabelecer um comparativo entre os momentos distintos da coleta dos depoimentos e, assim, observar a evolução ou mudança de pensamento do aluno durante o curso. Ademais, comparam-se, também, as definições apresentadas com aquelas expostas por alguns autores consagrados na literatura especializada (conhecimento teórico), caracterizando-se, assim, como uma pesquisa exploratória, bibliográfico-documental e qualitativa. Como resultado, percebeu-se, uma preferência dos alunos pelas escolas prescritivas nos dois momentos, com ênfase na escola de planejamento.

Palavras-chave: Conceito de estratégia. Estratégia. Estratégia empresarial.

\section{INTRODUÇÃO}

O conceito de estratégia começou a fazer parte do vocabulário das empresas em meados dos anos 50, devido ao aumento da velocidade das mudanças e da complexidade dos ambientes competitivos nos quais estavam inseridas, associando-se o termo 
estratégia à forma com a qual as organizações se relacionam com seu ambiente.

Em evolução, a partir da década de 1980, o conceito de estratégia passou por uma extensa revisão da qual emergiu o conceito de administração estratégica, em substituição à predominância do uso do termo planejamento estratégico (ANSOFF, 1965; ANSOFF; McDONNEL, 1993). Associado a evolução conceitual de estratégia, Mintzberg, Ahlstrand e Lampel (2010) promovem uma revisão de grande volume de literatura da qual emergem dez abordagens distintas, a maioria das quais se refletindo na prática gerencial e com uma perspectiva única que focaliza um aspecto importante do processo de formulação de estratégia.

Vale ressaltar, entretanto, que o termo estratégia ainda hoje é frequentemente usado com certo grau de coloquialismo, significando algumas vezes, um plano, um método para conseguir algo; outras vezes, é entendida como um jeito de ser, ou mesmo uma forma de pensar, tanto que Mintzberg, Ahlstrand e Lampel (2010, p. 16) lembram, com relação à palavra estratégia, que "hoje os gerentes a usam livre e afetuosamente."

Assim, o tema desenvolvido neste trabalho tem como eixo central a comparação entre o conhecimento tácito e o teórico acerca do que seja estratégia, a fim de observar como se dá a evolução ou mudança de pensamento do pesquisado com relação ao que expõem alguns autores consagrados. Justifica-se como um trabalho desafiador e de contribuição acadêmica relevante na medida em que oferece resultados, apurados por meio do software especializado em análise de conteúdo, de uma confrontação das definições dadas por alunos em nível de mestrado com o posiconamento de autores renomados, além de medir a influência das discussões teóricas na mudança de pensamento dos alunos. Pouco se conhece a respeito do pensamento de profissionais sobre o conceito de estratégia e o confronto deste conhecimento com conceitos consagrados na literatura.

Diante dessas considerações teóricas, o presente trabalho estabelece, como problema de pesquisa, a percepção do conceito de estratégia em pe- ríodos distintos, antes e após a disciplina, mediante auxílio de autores consagrados da área. Tem, como questão de partida: qual o entendimento de profissionais sobre o conceito de estratégia?

Após esta introdução, o artigo traz um referencial teórico abordando o campo da estratégia. Apresenta os procedimentos metodológicos que deram suporte a sua execução, caracterizando-o como um estudo exploratório, apoiado por uma pesquisa qualitativa, na qual lança-se mão do software Sphinx Léxica V-5, tendo, como fonte de evidência, as definições apresentadas por alunos antes e depois de se submeterem à disciplina Estratégia Empresarial, do Mestrado Profissional em Administração, bem como as definições apresentadas por autores consagrados. Por fim, através de vários quadros, faz-se comparações, análises e discussões das evidências obtidas, apresentando as conclusões e recomendações para trabalhos futuros.

\section{ESTRATÉGIA}

Estratégia empresarial é o padrão de decisões que determina e revela objetivos, propósito ou metas, produz as principais políticas e planos para obtenção dessas metas e define a escala de negócios em que a empresa deve se envolver (ANDREWS, 2001).

De outro modo, um dos conceitos mais genéricos e difundidos sobre o que é estratégia enfatiza-a como sendo o caminho escolhido pela organização para o atingimento de seus objetivos.

Assim, toda organização busca o alcance de determinados objetivos e, para tal fim, precisa dispor de estratégias sobre como fazê-lo. Essas estratégias, de forma geral, irão envolver maneiras de utilizar os recursos internos da organização no sentido do aproveitamento das oportunidades existentes no ambiente externo (CORDEIRO, 2005).

Talvez não haja nenhum outro processo nas empresas que seja mais exigente do ponto de vista da inteligência humana do que o desenvolvimento de estratégias. Na prática, esse processo está associado à busca do domínio do conhecimento sobre o negócio e os recursos da 
empresa, em seu ambiente operacional e institucional (CARVALHO; LAURINDO, 2003). Muito provavelmente por esse motivo, o conceito de estratégia venha sendo amplamente discutido na literatura pertinente, sem que, até hoje, se tenha chegado a uma definição universalmente aceita.

A ideia de estratégia nasceu das campanhas militares e seu entendimento sofreu alterações ao longo do tempo, percorrendo uma longa trajetória até os dias de hoje. Ressalte-se que o conceito de estratégia comporta várias aborda- gens e permanece em constante evolução, tanto na área militar como na área de negócios, na qual surgiu em torno de 1950, através de Von Neumann e Morgenstern, no contexto de sua famosa teoria dos jogos, florescendo nos anos de 1960/80 (ANSOFF, 1965; CARVALHO; LAURINDO, 2003).

A literatura acadêmica, por sua vez, é rica em se tratando de definições e significados para a palavra estratégia. O Quadro 1 traz algumas definições de autores consagrados.

\begin{tabular}{|l|r|}
\hline \multicolumn{1}{|c|}{ DEFINIÇÕES DE ESTRATÉGIA } & $\begin{array}{c}\text { AUTORES } \\
\text { CONSAGRADOS }\end{array}$ \\
\hline $\begin{array}{l}\text { Estratégia é a determinação dos objetivos básicos de longo prazo de uma empresa } \\
\text { e a adoção das ações adequadas e obtenção de recursos para atingir esses objetivos. }\end{array}$ & (CHANDLER, 1962). \\
\hline $\begin{array}{l}\text { O objetivo estratégico de uma empresa é obter retorno do capital, e se em um } \\
\text { caso específico o retorno ao longo prazo não for satisfatório, o defeito deve ser } \\
\text { corrigido ou a atividade deve ser abandonada. }\end{array}$ & (SLOAN, 1963). \\
\hline $\begin{array}{l}\text { Estratégia é um conjunto de regras de tomada de decisão em condições de des- } \\
\text { conhecimento parcial. As decisões estratégicas dizem respeito à relação entre a } \\
\text { empresa e o seu ecossistema. }\end{array}$ & (ANSOFF, 1965) \\
\hline $\begin{array}{l}\text { Estratégia competitiva são as ações ofensivas para criar uma posição defensável } \\
\text { numa indústria, para enfrentar com sucesso as forças competitivas e assim obter } \\
\text { um retorno maior sobre o investimento. }\end{array}$ & (PORTER, 1986). \\
\hline $\begin{array}{l}\text { Estratégia é uma força mediadora entre organização e o seu meio envolvente: } \\
\text { um padrão no processo de tomada de decisões organizacionais para fazer face } \\
\text { ao meio envolvente. }\end{array}$ & (MINTZBERG, 1987). \\
\hline $\begin{array}{l}\text { O padrão de decisão em uma companhia que determina e revela seus objetivos, } \\
\text { propósitos ou metas, produz as principais diretrizes e planos para atingir essas } \\
\text { metas, e define a amplitude dos negócios que a companhia persegue, o tipo } \\
\text { de organização econômica e humana que ela pretende ser, a natureza das con- } \\
\text { tribuições econômicas e não-econômicas que pretende proporcionar aos seus } \\
\text { acionistas, empregados, clientes e comunidades . }\end{array}$ & (ANDREWS, 2001) \\
\hline
\end{tabular}

Quadro 1 - Definições de estratégia

Fonte: adaptado de Marietto et al. (2006).

A partir de uma perspectiva mais ampla sobre o pensamento estratégico empresarial, da revisão de grande volume de literatura emergem dez pontos de vista distintos - dez escolas de pensamento - surgidos em estágios diferentes do desenvolvimento da administração, cada um tendo uma perspectiva única, focalizando um aspecto importante do processo de formulação de estratégia (MINTZBERG; AHLSTRAND; LAMPEL, 2010).
O Quadro 2 traz um resumo dessas escolas, com seus respectivos processos de formulação e característica. Estão, genericamente, agrupadas em função de sua característica: prescritiva, descritiva ou uma combinação de ambas. 


\begin{tabular}{|c|c|c|}
\hline NOME DA ESCOLA & $\begin{array}{c}\text { PROCESSO DE FORMULAÇAO } \\
\text { DE ESTRATÉGIA }\end{array}$ & CARACTERÍSTICA \\
\hline $\begin{array}{c}\text { Design } \\
\text { Planejamento } \\
\text { Posicionamento }\end{array}$ & $\begin{array}{c}\text { Concepção } \\
\text { Formal } \\
\text { Analítico } \\
\end{array}$ & $\begin{array}{l}\text { Prescritiva - a estratégia deve ser } \\
\text { como um receituário, passível de ser } \\
\text { repetidamente usado }\end{array}$ \\
\hline $\begin{array}{c}\text { Empreendedora } \\
\text { Cognitiva } \\
\text { Aprendizado } \\
\text { Poder } \\
\text { Cultural } \\
\text { Ambiental }\end{array}$ & $\begin{array}{l}\text { Visionário } \\
\text { Mental } \\
\text { Emergente } \\
\text { Negociação } \\
\text { Coletivo } \\
\text { Reativo }\end{array}$ & $\begin{array}{l}\text { Descritiva - a estratégia não deve } \\
\text { ser uma receita, mas, sim, auxiliar } \\
\text { na formação do julgamento e da } \\
\text { intuição }\end{array}$ \\
\hline Configuração & Transformação & $\begin{array}{lll}\begin{array}{l}\text { Combina } \\
\text { anteriores }\end{array} & \text { as } & \text { características } \\
\end{array}$ \\
\hline
\end{tabular}

Quadro 2 - As escolas de pensamento estratégico

Fonte: adaptado de Mintzberg, Ahlstrand e Lampel (2010).

Assim, a palavra estratégia, para não mencionar dez escolas tão diferentes a seu respeito, requer, em particular, cinco definições. A primeira delas, apresenta estratégia como um plano, ou algo equivalente, uma direção, um guia ou curso de ação para o futuro (estratégia pretendida). A segunda explicita estratégia como um padrão, isto é, comportamento consistente ao longo do tempo (estratégia realizada).

No tocante a essas duas definições, a
Figura 1 mostra que as intenções plenamente realizadas são chamadas de estratégias deliberadas; as não realizadas, de estratégias irrealizadas. Existem, ainda, as estratégias emergentes, onde um padrão realizado não era expressamente pretendido. Nesse caso, foram tomadas providências, uma a uma, que convergiram com o tempo para algum tipo de consistência ou padrão (MINTZBERG; AHLSTRAND; LAMPEL, 2010).

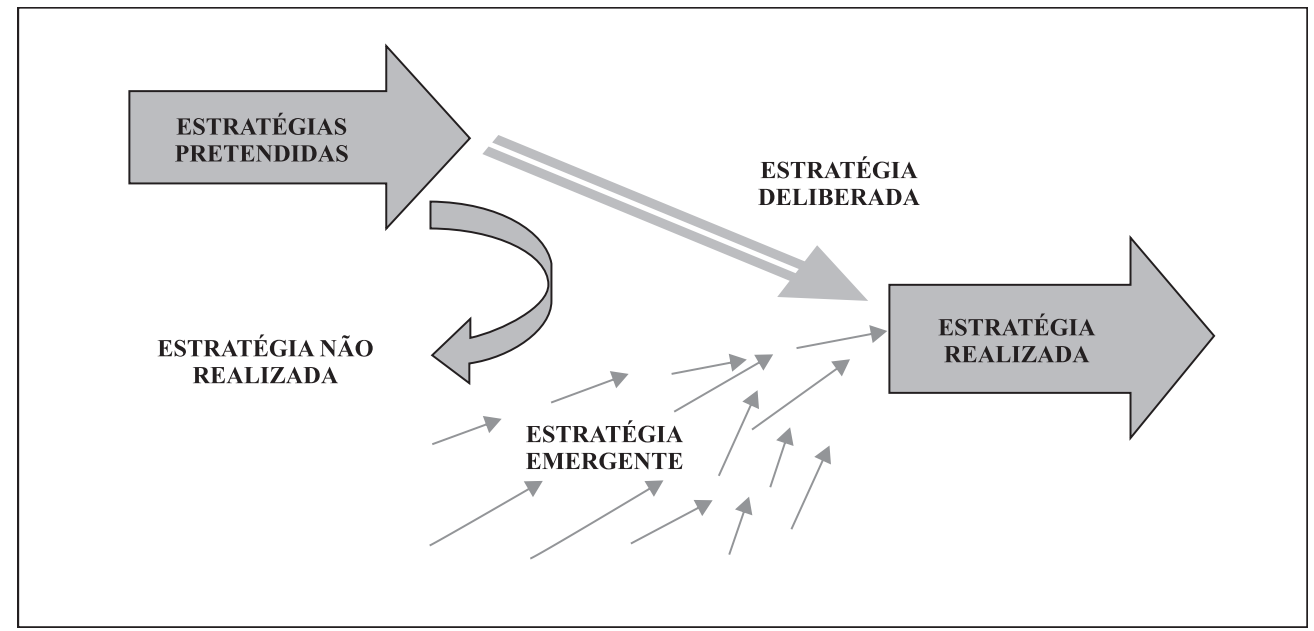

Figura 1 - Estratégias deliberadas e emergentes

Fonte: Mintzberg, Ahlstrand e Lampel (2010, p. 19).

Como lembra Toscani e Steiner Neto (2007), formulação e implementação de estratégia resultam em um processo contínuo de aprendizagem em que surgem estratégias criati- vas e eficazes, onde o pensamento não deve se desconectar da ação. Dessa forma, durante a implementação das estratégias deliberadas, surgem estratégias emergentes que são fruto das relações 
da organização com o ambiente. Isso significa que a estratégia efetivamente realizada é a soma das estratégias deliberadas e emergentes, e não à implementação pura e simples da estratégia inicialmente formulada (pretendida).

A terceira definição enuncia que estratégia é uma posição, isto é, a localização de determinados produtos em determinados mercados; e a quarta definição, expõe que estratégia é uma perspectiva, isto é, a maneira fundamental de uma organização fazer as coisas. Por último, ainda há uma quinta definição, dando conta da estratégia como um truque, isto é, uma manobra específica para enganar um oponente ou concorrente (MINTZBERG; AHLSTRAND; LAMPEL, 2010).

\subsection{AS DEZ ESCOLAS}

Dadas as cinco definições (os cinco P's da estratégia), faz-se, a seguir, uma breve análise de cada uma das dez escolas de pensamento.

\subsubsection{Escola do design}

Apresenta a estratégia como um processo de concepção. Seus autores mais influentes são Selznick (1957), Chandler (1962) e Andrews (1965). Representa a visão mais influente do processo de formação estratégica, cujos conceitos-chave embasam cursos de graduação e mestrado em estratégia, bem como grande parte da prática da administração estratégica. (MINTZBERG; AHLSTRAND; LAMPEL, 2010).

Para Carvalho e Laurindo (2003, p. 14), "foi o pensamento dominante nos anos 1960 e começo dos anos 1970."

Dando ênfase às avaliações das situações interna e externa, essa escola propõe um modelo, conhecido por SWOT, de formulação de estratégia que busca atingir uma adequação entre capacidades internas - avaliando pontos fortes (strengths) e pontos fracos (weaknesses) - e possibilidades externas - refletidas pelas oportunidades (opportunities) e ameaças (threats). Referido modelo é peça central da maior parte dos livros-texto a despeito do desenvol- vimento e do crescimento em várias direções da administração estratégica (MINTZBERG; AHLSTRAND; LAMPEL, 2010).

$\mathrm{Na}$ verdade, trata-se de um ajuste entre forças e fraquezas presentes no âmbito interno à organização, e entre ameaças e oportunidades que fazem parte do meio externo.

Além desses fatores, o modelo básico dessa escola mostra dois outros considerados importantes na formação da estratégia: um, sobre os valores gerenciais (crenças e preferências daqueles que lideram a organização); e outro, com respeito às responsabilidades sociais - especificamente a ética da sociedade na qual a organização opera, pelo menos como ela é interpretada por seus executivos (MINTZBERG; AHLSTRAND; LAMPEL, 2010).

Algumas premissas básicas sustentam essa escola:

a) a formação da estratégia deve ser um processo deliberado de pensamento consciente;

b) a responsabilidade por esse controle e essa percepção deve ser do executivo principal (essa pessoa é o estrategista);

c) o modelo da formação de estratégia deve ser mantido simples e informal;

d) as estratégias devem ser únicas: as melhores resultam de um processo de design individual; e) o processo de design está completo quando as estratégias parecerem plenamente formuladas como perspectiva;

e) essas estratégias devem ser explícitas; assim, precisam ser mantidas simples;

f) somente depois que essas estratégias únicas, desenvolvidas, explícitas e simples são totalmente formuladas é que elas podem ser implementadas (LEARNED et al., 1965 apud MINTZBERG; AHLSTRAND; LAMPEL, 2010).

Pelo exposto, percebe-se, claramente, que essa escola prima por um processo de pensamento humano rigidamente controlado pelo executivo principal, que é o estrategista da organização, trabalhando um modelo simples, 
específico e individualizado de formulação da estratégia, no qual é oferecido pouco espaço para as estratégias emergentes, separando-se, nitidamente, formulação de implementação.

Como crítica à escola do design, a despeito de suas contribuições ao desenvolver importante vocabulário para se discutir grandes estratégias e fornecer a noção central subjacente à grande parte da prescrição no campo da administração estratégica, destacam-se: o perigo de se estreitar a perspectiva de uma organização ao colocá-la em um nicho; e o fato de se negar a importância do desenvolvimento incremental, da estratégia emergente, da influência da estrutura existente sobre a estratégia, da plena participação de outros atores além do executivo principal (MINTZBERG; AHLSTRAND; LAMPEL, 2010).

\subsubsection{Escola de Planejamento}

Apresenta a estratégia como um processo formal. Seu surgimento se deu ao mesmo tempo em que o da escola do design, sendo Ansoff (1965) seu livro mais influente (MINTZBERG; AHLSTRAND; LAMPEL, 2010).

Carvalho e Laurindo (2003) reportam-se a essa escola dizendo que ela teve seu apogeu nos anos setenta do século passado, decaindo de importância a partir da década seguinte. Entretanto, vale ressaltar, trata-se ainda hoje de uma importante escola de pensamento estratégico.

A maior parte dos modelos básicos de planejamento estratégico, dentre as centenas existentes, se reduz às mesmas idéias básicas que envolvem o modelo SWOT dividido em etapas claramente delineadas e articuladas, dando-se especial atenção à fixação de objetivos, no início, e à elaboração de orçamentos e planos operacionais, no final.

Assim, todo o processo se inicia a partir do estabelecimento de objetivos, verificando-se, em seguida, as condições internas e externas, para, posteriormente, se avaliar as estratégias e escolher uma delas, que será decomposta em subestratégias a serem implementadas, obedecendo-se a uma programação das várias etapas. Uma síntese das premissas da escola de planejamento:

a) as estratégias devem resultar de um processo controlado e consciente de planejamento formal, em etapas distintas, delineadas por checklists e apoiada por técnicas;

b) a responsabilidade por todo o processo é, em princípio, do executivo principal, muito embora, na prática, a responsabilidade pela execução seja dos planejadores;

c) as estratégias surgem prontas deste processo, devendo ser explicitadas para que possam ser implementadas por meio da atenção detalhada a objetivos, orçamentos, programas e planos operacionais (MINTZBERG; AHLSTRAND; LAMPEL, 2010).

Como crítica, não ao planejamento, mas ao planejamento estratégico, como se a estratégia pudesse ser desenvolvida em um processo estruturado e formalizado, Mintzberg, Ahlstrand e Lampel (2010, p. 64) assim se posicionam: "nenhuma elaboração jamais fará com que procedimentos formais possam prever descontinuidades, informar gerentes distanciados, criar novas estratégias. Assim o planejamento, ao contrário de prover novas estratégias, não pode prosseguir sem sua existência prévia."

\subsubsection{Escola do Posicionamento}

O ano de 1980 representou um divisor de águas, com a publicação do livro de Porter (1980). Essa obra, aglutinou os interesses de uma geração de acadêmicos e consultores, e dá sustentação à terceira escola de pensamento estratégico. Recebe o nome de escola de posicionamento, possui característica prescritiva, e encara a estratégia como um processo analítico (MINTZBERG; AHLSTRAND; LAMPEL, 2010).

Carvalho e Laurindo (2003) ensinam que essa escola, na qual o estrategista é, sobretudo, um analista, baseia-se na ideia de que a estratégia pode ser reduzida a algumas posições genéricas identificáveis através da análise da situação da indústria. 
Para Mintzberg, Ahlstrand e Lampel (2010, p. 69), “a noção de que a estratégia precede a estrutura também foi mantida nesta escola. Mas outra forma de 'estrutura', a da indústria, foi acrescentada, de forma que a estrutura da indústria dirigia a posição estratégica, que, por sua vez, dirigia a estrutura organizacional."

Percebe-se que, para essa corrente de pensamento, a formulação da estratégia deve ser precedida de um profundo exame do setor (ambiente externo) em que se insere a empresa.

Para obter lucro econômico superior, uma empresa deve ter posição superior em um setor que gera retorno médio ou uma posição média em um setor que gera retorno superior, sendo que posição superior em um setor superior é raro e especialmente rentável (DRANOVE; MARCIANO, 2007).

Vale salientar, ainda, que tanto a atratividade do setor quanto a posição competitiva podem ser modeladas por determinada empresa, o que torna desafiante e excitante a escolha da estratégia competitiva, já que esta não só responde ao meio ambiente, mas, também, tenta modelar esse meio ambiente em favor de uma empresa (PORTER, 1989).

Ou seja, o que mais importa na formulação de uma estratégia competitiva é relacionar uma determinada empresa ao seu meio ambiente, cujo aspecto principal é o setor ou setores onde ela compete.

O grau da concorrência em uma indústria depende de cinco forças competitivas básicas, que, em conjunto, determinam o potencial de lucro final na indústria, que é medido em termos de retorno em longo prazo sobre o capital investido. Essas cinco forças são:

a) ameaças de novos entrantes;

b) poder de negociação dos compradores;

c) ameaça de produtos/serviços substitutos;

d) poder de negociação dos fornecedores e;

e) a rivalidade entre as empresas existentes.

Assim, a estratégia competitiva visa a en- contrar uma posição dentro de uma determinado setor em que a companhia melhor se defenda contra estas forças competitivas ou seja influenciada por elas a seu favor (PORTER, 1986).

Portanto, diagnosticadas as forças presentes em um setor, o próximo passo seria a empresa mapear seus pontos fortes e fracos em relação a esse mesmo setor.

Importa lembrar aqui, de acordo com Zilber et al. (2006), que alguns autores incluem uma sexta força, representada pelos demais stakeholders (governo, empregados, comunidade local, credores que não os fornecedores, associações de classe, grupos com interesses especiais e acionistas) que também concorrem pela rentabilidade da indústria.

Em sentido mais amplo, três estratégias genéricas podem ser utilizadas por uma empresa, de forma isolada ou combinadas, com o intuito de criar uma posição defensável a longo prazo e superar seus concorrentes. São elas:

a) liderança no custo total;

b) diferenciação e;

c) enfoque (PORTER, 1986, 1989).

Porter (1989) também introduz o conceito de cadeia de valor, instrumento básico para o exame sistemático das atividades executadas por uma empresa e do modo como elas interagem.

Algumas críticas à escola de posicionamento:

a) o foco é estreito, orientado para o econômico e, em especial, para o quantificável, em detrimento do social, político, ou mesmo do econômico não-quantificável;

b) o contexto também é estreito, inclinando-se para situações onde o poder de mercado é maior, a concorrência menos eficaz e o potencial para manipulação política mais pronunciado;

c) o processo - a mensagem da escola de posicionamento não é ir lá fora e aprender, mas ficar nos escritórios e calcular;

d) a própria estratégia tende a ter um foco estreito nessa escola, pois é vista como uma posição genérica, não uma perspectiva única. 
Há de se considerar, porém, que a escola de posicionamento trouxe uma importante contribuição à administração estratégica, abrindo enormes possibilidades em termos de pesquisas, agregando um poderoso conjunto de conceitos à prática (MINTZBERG; AHLSTRAND; LAMPEL, 2010).

Percebe-se que Porter $(1986,1989)$ centra toda a sua abordagem na análise do ambiente externo à organização. Entretanto, conforme cita Popadiuk (2007), outra abordagem, focada no ambiente interno, conhecida com Resource Based View-RBV (Wernerfelt, 1984), estabelece que os recursos, competências e capacidades de uma organização são os fatores fundamentais para um posicionamento superior ao dos concorrentes. Nessa perspectiva, os recursos tangíveis e intangíveis devem ser objeto de gerenciamento, de modo a proporcionar à organização um desempenho competitivo, preferencialmente, superior ao da concorrência.

Ou seja, as abordagens da organização industrial (ênfase nos fatores externos) e da visão baseada em recursos (ênfase nos aspectos internos) se configuram em duas linhas básicas de referência para o desenvolvimento de pesquisas em estratégia, principalmente com foco na identificação dos fatores que influenciam o desempenho da organização (GONÇALVES; DIAS; MUNIZ, 2008).

\subsubsection{Escola empreendedora}

Concluídas as três escolas prescritivas, inicia-se, pela escola empreendedora, o estudo daquelas caracterizadas como descritivas.

Ocupando uma posição intermediária entre as prescritivas e as descritivas, adota uma visão não totalmente diversa daquela que caracteriza a escola do design, e encara a formação de estratégia como um processo visionário (MINTZBERG; AHLSTRAND; LAMPEL, 2010).

Segundo Carvalho e Laurindo (2003, p. 14), essa escola "[...] foca o processo no principal executivo da empresa [...]. Contudo, de maneira bastante diversa, fundamenta o processo na intuição criativa de um líder visionário e na sua capacidade de controlar a implementação de suas idéias."

O conceito central da escola empreendedora é a visão - uma representação mental, criada ou ao menos expressa na cabeça do líder - acerca da estratégia. É uma inspiração, um senso daquilo que precisa ser feito, e tende, com freqüência, a ser mais uma espécie de imagem do que um plano totalmente articulado em palavras e números. Tal fato enseja flexibilidade, possibilidades de adaptações por parte do líder às suas próprias experiências. Assim, a estratégia empreendedora é, ao mesmo tempo, deliberada (em suas linhas amplas e seu senso de direção) e emergente (em seus detalhes para que estes possam ser adaptados durante o curso) (MINTZBERG; AHLSTRAND; LAMPEL, 2010).

Um breve resumo, segundo Mintzberg, Ahlstrand e Lampel (2010), das premissas subjacentes à escola empreendedora:

a) a estratégia existe, como perspectiva (senso de direção em longo prazo, visão de futuro da organização), na mente do líder;

b) processo semiconsciente de formulação da estratégia ancorado na experiência e na intuição do líder, concebido ou não por ele;

c) o líder promove a visão e mantém controle pessoal de sua implementação;

d) a visão estratégica é maleável e, portanto, a estratégia empreendedora tende a ser deliberada e emergente;

e) a organização é igualmente maleável - uma estrutura simples, sensível às diretrizes do líder;

f) a estratégia empreendedora tende a assumir a forma de nicho - um ou mais bolsões de posição no mercado protegidos contra as forças de concorrência direta.

A despeito de que em algumas situações (pequenas empresas ou empresas recentemente criadas, por exemplo) faz-se necessária uma liderança vigorosa, personalizada, percebe-se, como crítica a essa linha de pensamento estratégico, algumas deficiências sérias, ressal- 
tando-se, dentre elas, o fato de que a estratégia é inteiramente calcada no comportamento de um único indivíduo sem que se possa dizer muito sobre qual é o processo (MINTZBERG; AHLSTRAND; LAMPEL, 2010).

\subsubsection{Escola Cognitiva}

A escola cognitiva adota a formação da estratégia como um processo mental, cujo trabalho, para Mintzberg, Ahlstrand e Lampel (2010), é entender o que significa estratégia na esfera da cognição humana, utilizando, em especial, a psicologia cognitiva. Caracteriza-se muito mais pelo seu potencial do que pela sua contribuição.

Tendo surgido nos anos oitenta do século passado, continua, ainda hoje, em desenvolvimento, baseando-se no modo como a realidade é percebida. Mais recentemente, seu foco está direcionado para uma abordagem mais subjetiva, interpretativa ou construtivista do processo de formulação da estratégia (CARVALHO; LAURINDO, 2003).

Ou seja, essa escola pretende desvendar o processo mental de criação das estratégias ao analisar a sua formação na cabeça do estrategista.

A escola cognitiva, de acordo com Mintzberg, Ahlstrand e Lampel (2010), encontra-se ainda no estágio de evolução sobre formação de estratégia. Suas premissas são:

a) a formação da estratégia é um processo cognitivo que ocorre na mente do estrategista;

b) as estratégias emergem como perspectivas, na forma de conceitos, mapas, esquemas e molduras, que moldam a maneira pela qual as pessoas lidam com informações vindas do ambiente;

c) de acordo com a ala 'objetiva' dessa escola, essas informações fluem através de todos os tipos de filtros deturpadores antes de serem decodificadas pelos mapas cognitivos, ou, de acordo com a ala 'subjetiva', são apenas interpretações de um mundo que existe somente em termos de como é percebido; d) como conceito, as estratégias são difíceis de serem realizadas, ficando, quando realizadas, abaixo do ponto ótimo e, subsequentemente, tornando-se difíceis de serem mudadas quando não mais são viáveis.

Como crítica, Mintzberg, Ahlstrand e Lampel (2010) apontam que a administração estratégica ainda precisa ganhar o suficiente da psicologia cognitiva, ou de outra forma, a psicologia cognitiva ainda precisa resolver de forma adequada as questões de maior interesse para a administração estratégica, em especial como se formam os conceitos na mente do estrategista.

\subsubsection{Escola de aprendizado}

Encara a formação da estratégia como um processo emergente, sugerindo que, diante da complexidade do mundo da estratégia, os estrategistas aprendem ao longo do tempo (MINTZBERG; AHLSTRAND; LAMPEL, 2010).

Para essa escola, a estratégia é um processo que emerge na organização como um todo, a partir de seus membros, de modo individual ou coletivamente.

Para Carvalho e Laurindo (2003), essa escola desenvolve-se em paralelo a outras, assumindo, de certa forma, uma posição desafiadora à escola dominante em cada momento da história. Possuindo uma visão incremental do processo de implantação da estratégia, entende que os estrategistas podem estar presentes em qualquer parte da organização não se admitindo uma separação entre a formulação e implementação da estratégia.

Assim, nasce, com essa escola, um debate, acerca de quem é realmente o arquiteto da estratégia; onde, na organização, ocorre de fato a formação de estratégia; até que ponto o processo é realmente deliberado e consciente; e se existe de fato, e é sagrada, a separação entre formulação e implementação (MINTZBERG; AHLSTRAND; LAMPEL, 2010).

Mintzberg, Ahlstrand e Lampel (2010) inferem as seguintes premissas da escola de aprendizado: 
a) a natureza complexa e imprevisível do ambiente da organização impede o controle deliberado, levando a que a formação da estratégia assuma a forma de um processo de aprendizado ao longo do tempo, onde, no limite, formulação e implementação se tornam indistinguíveis;

b) em geral, é o sistema coletivo - inclusive o líder - que aprende;

c) esse aprendizado ocorre de forma emergente através de um comportamento que estimula o pensamento retrospectivo para que se possa compreender a ação;

d) a liderança não preconcebe estratégias deliberadas, mas gerencia o processo de aprendizado estratégico, através do qual novas estratégias emergem;

e) as estratégias aparecem, inicialmente, como padrões do passado; mais tarde, talvez, como planos para o futuro e, finalmente, como perspectiva para guiar o comportamento geral.

Como crítica a essa escola, Mintzberg, Ahlstrand e Lampel (2010) apontam os perigos de se ir ao extremo oposto - desintegração da estratégia - face à inexistência de estratégia (muitas organizações sofrem por falta de uma estratégia claramente articulada), estratégia perdida (excesso de ênfase na aprendizagem pode servir para minar uma estratégia coerente e perfeitamente viável), ou estratégia errada (aprender de modo incremental pode também estimular o surgimento de estratégias que ninguém nunca quis e muito menos pretendeu implementar).

\subsubsection{Escola do poder}

A escola de poder prega a formulação da estratégia como um processo de negociação, onde a palavra poder é utilizada com o intuito de descrever o exercício da influência além daquela puramente econômica.

Segundo Carvalho e Laurindo (2003), essa escola, que não se classifica entre as maio- res, enxerga o poder, em uma abordagem micro, sendo disputado internamente nas organizações, através de um processo de natureza política que envolve negociação, persuasão e barganhas. Já em uma abordagem macro, vê a organização como uma entidade que usa seu poder a fim de estabelecer parcerias, joint ventures ou outros inter-relacionamentos para negociar estratégias coletivas que sejam de seu interesse.

Mintzberg, Ahlstrand e Lampel (2010) postulam as seguintes premissas para essa escola:

a) a formação da estratégia é moldada por poder e política;

b) as estratégias tendem a ser emergentes, assumindo mais a forma de posições e meios de iludir do que de perspectivas;

c) o poder micro vê a formação de estratégia como a interação entre interesses estreitos e coalizões inconstantes e;

d) o poder macro vê a organização como promovendo seu próprio bem-estar por controle ou cooperação com outras organizações.

Como crítica, Mintzberg, Ahlstrand e Lampel (2010) lembram que, embora seja verdade que a dimensão política pode ter um papel positivo nas organizações, ela também pode ser a fonte de muito desperdício e distorção. Ou seja, a formação da estratégia deve envolver poder, mas não somente, de modo a não se desprezar o papel de forças integradoras, tais como liderança e cultura, que tende a ser desprezado por essa escola, assim como a noção em si de estratégia.

\subsubsection{Escola cultural}

Assume a formação da estratégia como um processo coletivo e, de acordo com Mintzberg, Ahlstrand e Lampel (2010, p. 194), "preocupa-se em grande parte com a influência da cultura na manutenção da estabilidade estratégica e, em alguns casos, resistindo ativamente às mudanças estratégicas."

Essa escola considera a estratégia como um processo social, baseado na cultura, tratando dos interesses comuns e da integração. $\mathrm{Na}$ maior parte dos seus textos, trata da influência 
da cultura como inibidora de mudanças estratégicas mais significativas (CARVALHO; LAURINDO, 2003).

Suas principais premissas são:

a) a formação de estratégia é um processo de interação social, baseado nas crenças e interpretações comuns aos membros de uma organização;

b) as crenças são adquiridas por meio de um processo de aculturação ou socialização em grande parte tácito e não verbal;

c) as origens e explicações dessas crenças podem permanecer obscuras, ou seja, os membros da organização podem descrever apenas parcialmente aquelas que sustentam sua cultura;

d) a estratégia é do tipo perspectiva/deliberada, enraizada em intenções coletivas e;

e) a cultura e a ideologia não encorajam tanto as mudanças estratégicas quanto a perpetuação da estratégia existente (MINTZBERG; AHLSTRAND; LAMPEL, 2010).

Como crítica, falta a essa escola clareza conceitual, possibilitando desencorajar mudanças necessárias, favorecendo a administração da consistência, a permanência nos trilhos, a ênfase na tradição e no consenso, além de caracterizar as mudanças como sendo complexas e difíceis (MINTZBERG; AHLSTRAND; LAMPEL, 2010).

\subsubsection{Escola ambiental}

Encara a estratégia como um processo reativo, considerando o conjunto de forças fora da organização (ambiente externo) não um fator, mas o ator (MINTZBERG; AHLSTRAND; LAMPEL, 2010). Busca-se, nessa escola:

[...] entender quais os graus de liberdade da empresa para se movimentar dentro de seu ambiente, bem como quais são as demandas deste meio ambiente. Incluem-se aqui a chamada Teoria da Contingência (que estuda quais as respostas esperadas das empresas de determinadas condições ambientais) e Teoria Institucional (que estuda as pressões institucionais enfrentadas pelas organizações). (CARVALHO; LAURINDO, 2003, p. 15).

Suas principais premissas, à luz do que diz Mintzberg, Ahlstrand e Lampel (2010), são:

a) o ambiente é o agente central no processo de geração de estratégia;

b) as organizações devem responder ao conjunto de forças que compõe o ambiente;

c) a liderança é um elemento passivo na leitura do ambiente e na garantia de uma adaptação adequada por parte da organização;

d) as organizações acabam assumindo posições nas quais permanecem até que os recursos se tornem escassos ou as condições demasiado hostis, e morrem.

Como crítica, Mintzberg, Ahlstrand e Lampel (2010) assinalam que, ao modo da teoria contingencial - pelo menos para fins de administração estratégica, essa escola dimensiona o ambiente de forma muito abstrata, vaga e agregada, quando a estratégia tem a ver com a seleção de posições específicas.

\subsubsection{Escola de configuração}

O terceiro e último grupo de escolas de pensamento estratégico contém apenas uma que, na realidade, combina ideias defendidas pelas demais. Denomina-se escola de configuração, e percebe a estratégia como um processo de transformação (MINTZBERG; AHLSTRAND; LAMPEL, 2010).

Há dois aspectos nessa escola que se complementam mutuamente, um mais acadêmico e outro mais profissional, com nuances de consultoria. O primeiro aspecto, mais descritivo, entende a empresa como uma configuração para cada situação, integrando as diferentes visões de cada escola, todas passíveis de serem usadas, conforme o caso. O segundo aspec- 
to mais prescritivo, vê as mudanças como transformações dramáticas de um estado par outro. (CARVALHO; LAURINDO, 2003, p. 15).

Suas premissas, segundo Mintzberg, Ahlstrand e Lampel (2010), são:

a) na maior parte das vezes, uma organização pode ser descrita segundo algum tipo de configuração estável de suas características: para um determinado período de tempo, ela adota uma estrutura adequada a um tipo de contexto, o que faz com que ela assuma certos comportamentos que, por sua vez, originam um particular conjunto de estratégias;

b) esses períodos de estabilidade são ocasionalmente interrompidos por algum processo de transformação;

c) estados sucessivos de configuração e períodos de transformação podem se ordenar no tempo em seqüências padronizadas;

d) a chave para a administração estratégica é sustentar a estabilidade ou, no mínimo, mudanças estratégicas adaptáveis a maior parte do tempo, reconhecer periodicamente a necessidade de transformação, gerenciando esse processo de ruptura sem destruir a organização;

e) a geração de estratégia pode ser de concepção conceitual ou planejamento formal, análise sistemática ou visão estratégica, aprendizado cooperativo ou politicagem competitiva, focalizando cognição individual, socialização coletiva ou a simples reposta às forças do ambiente, cada um em seu próprio tempo e contexto;

f) as estratégias resultantes assumem a forma de planos ou padrões, posições ou perspectivas ou meios de iludir, porém, mais uma vez, cada um a seu tempo e adequado a sua situação.

A crítica mais aguda à escola de configuração vem de Donaldson (1996 apud MINTZBERG; AHLSTRAND; LAMPEL, 2010, p. 251), quando diz que "as configurações representam uma abordagem falha à teorização, precisamente porque são muito fáceis de entender e ensinar".

Além das escolas relacionadas anteriormente, outras correntes de pensamento estratégico estão ganhando evidência. Focalizam a implementação em vez da formulação (separação essa mais de caráter didático). São elas: Balanced Scorecard (BSC); (KAPLAN; NORTON, 1997); Administração por Autocontrole (DRUCKER, 1975); Destruição Criativa (FOSTER; KAPLAN, 2001); Modelos de Ruptura ou "Disruptivos" (CHRISTENSEN; OVERDORF, 2000), dando mostras de que o pensamento estratégico está em permanente evolução (HURST, 2001 apud CARVALHO; LAURINDO, 2003).

\section{METODOLOGIA}

Tratando-se de uma pesquisa que objetiva conhecer melhor o pensamento profissional a respeito do conceito de estratégia, o estudo em questão caracteriza-se, quanto aos objetivos, como exploratório e, quanto aos procedimentos de coleta, como bibliográfico-documental e de campo (GONSALVES, 2007). Utilizou-se, como instrumento de coleta, de um questionário contendo uma questão aberta, por meio da qual os alunos da disciplina Estratégia Empresarial do Mestrado Profissional de universidade pública cearense deveriam expor suas opiniões a respeito do significado do conceito de estratégia, baseados em leituras anteriormente feitas e em suas experiências profissionais e pessoais. O referido questionário foi aplicado no início e no final do curso, obtendo-se, assim, dois grupos de avaliações que foram posteriormente confrontadas. Comparam-se, também, as definições apresentadas pelos alunos com aquelas expostas por alguns autores consagrados na literatura especializada (conhecimento teórico).

A disciplina, ministrada para 21 (vinte e um alunos) teve, como objetivo, a obtenção de um embasamento conceitual-crítico a respeito do conhecimento sobre estratégia empresarial, de forma a subsidiar o desenvolvimento dos 
trabalhos relativos ao mestrado em administração, e tratou dos seguintes assuntos: conceituação sobre estratégia, visão baseada em recursos, vantagem competitiva, processo decisório, alianças estratégicas e estratégias funcionais, além de abordar exemplos práticos de trabalhos com estratégia.

Com relação à natureza dos dados, foi escolhido o método de pesquisa qualitativa embora tenham sido utilizados gráficos para demonstrar a contagem das palavras, um procedimento comum ao se utilizar análise de conteúdo - com intuito de compreender melhor o problema estudado, já que possibilita identificar ou antecipar oportunidades e problemas de forma bem mais pontual e precisa a partir da exploração de um dado completamente espontâneo (FREITAS, 2004; GONSALVES, 2007).

Com o auxílio do software Sphinx Léxica-V5, as respostas dos alunos, antes e depois da disciplina, bem como as definições dadas por autores consagrados foram catalogadas e avaliadas pelos participantes deste trabalho em rodadas sucessivas de discussões até se chegar a um consenso, classificando-se essas definições segundo as premissas de cada escola de pensamento apresentadas no referencial teórico, com foco apontado para a característica que mais se sobressaiu. Por fim, efetuou-se também uma análise do léxico das definições apresentadas.

\section{ANÁLISE DOS RESULTADOS}

O gráfico 1 apresenta uma classificação da opinião dos estudantes, segundo as escolas, no início da disciplina. Percebe-se uma maior concentração na escola do planejamento, com $39,13 \%$, seguida da escola do design, com $36,96 \%$. Em terceiro lugar aparece a escola do posicionamento, com um índice de $10,87 \%$, bem inferior àqueles das duas escolas mais votadas e próximas ao da escola empreendedora que alcançou $8,79 \%$. Por último, aparecem as escolas cultural e ambiental, cada uma com 2,17\%.

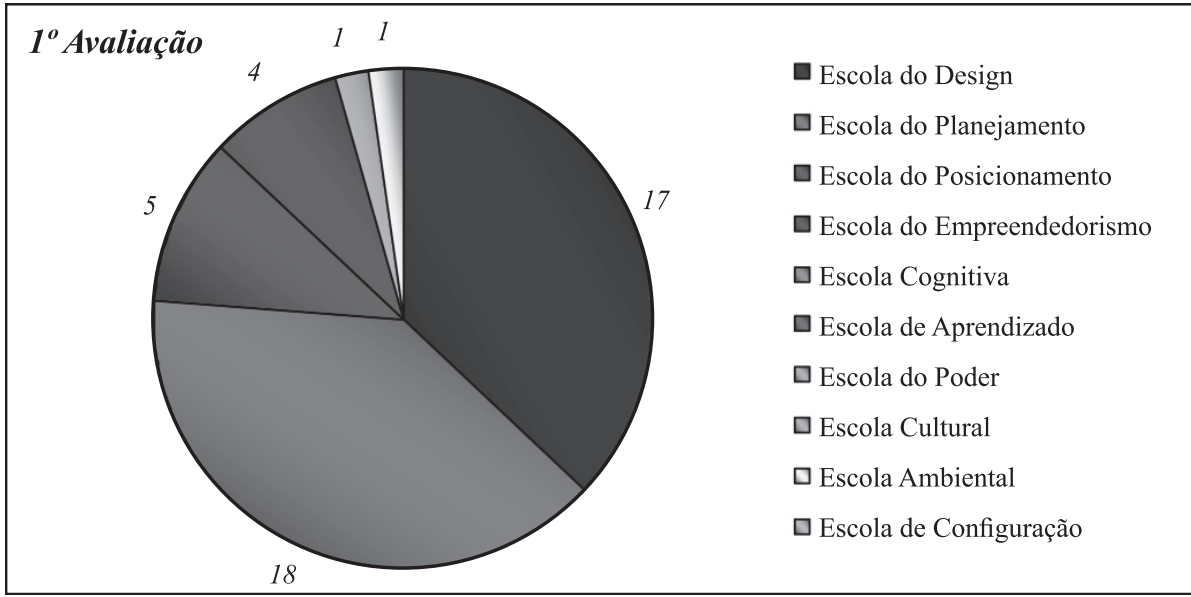

Gráfico 1 - Classificação das definições dos alunos no início da disciplina Fonte: dados da pesquisa (2009).

Não foram citadas as escolas cognitivas, $\mathrm{o}$ aprendizado, o poder e a configuração. Isso mostra que as definições apresentadas no início do curso se dirigem mais para as escolas prescritivas, principalmente a de planejamento, indicando a associação que popularmente se faz entre estratégia e planejamento. Percebe-se, também, a forte influência da escola do planejamento no pensamento estratégico, em particular, na formação básica dos profissionais. Entre as escolas descritivas, a que mais se sobressaiu foi a empreendedora, seguida pela cultural e ambiental, ambas com valores quase inexpressíveis.

O Gráfico 2 apresenta a classificação da opinião dos estudantes, segundo as escolas, desta vez ao final da disciplina. Esta distribui- 
ção já mostra uma maior diversificação das opiniões, mas os resultados ainda apontam para uma maioria da escola do planejamento, com $29,79 \%$, apesar de uma queda em torno de 10 p.p. Observa-se um crescimento significativo, em torno de 13 p.p., da escola empreendedora, que alcançou $21,28 \%$. As escolas do design, que caiu significativamente (quase 20 p.p.), e do posicionamento, que subiu em torno de 7 p.p., alcançaram, cada uma, 17,02\%. Entre as descritivas, a escola do poder, não citada antes, surge com 8,51\%; a ambiental consegue dobrar seu índice, alcançando 4,26\%, e a do aprendizado, também não citada antes, atinge $2,13 \%$. Não foram citadas as escolas cognitiva, cultural (antes citada) e de configuração. Por fim, é visível a evolução da diversificação conceitual por parte dos alunos ao final da disciplina ministrada, uma vez que surgem escolas que não foram citadas na primeira avaliação, indicando um aumento da abrangência do conceito de estratégia dos participantes.

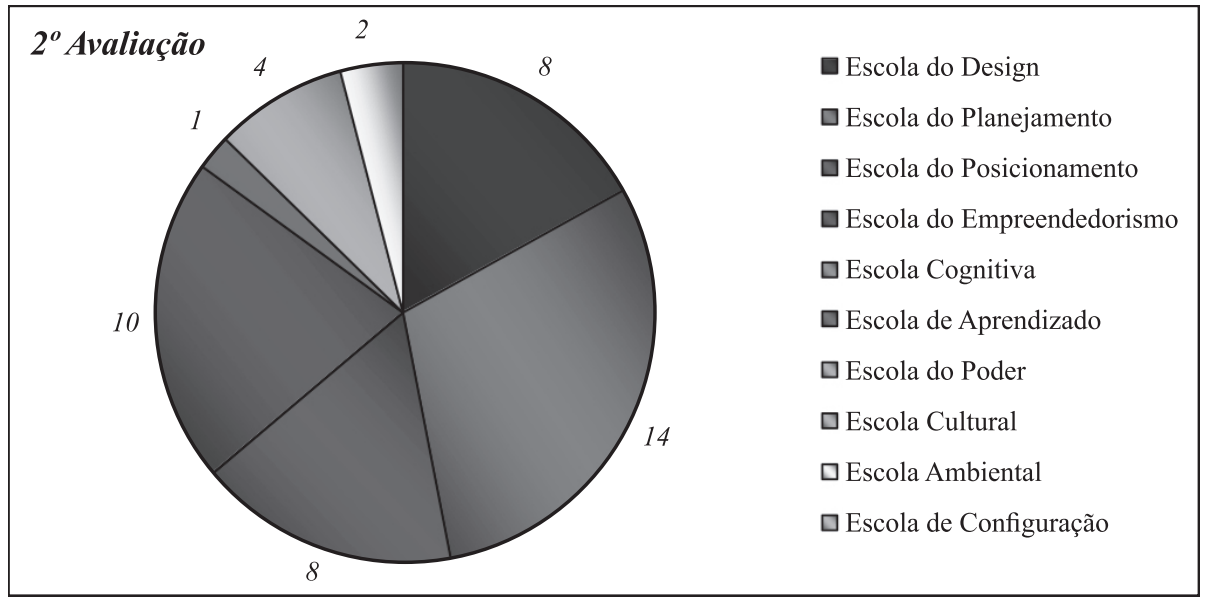

Gráfico 2 - Classificação das definições dos alunos ao final da disciplina Fonte: dados da pesquisa (2009).

O Gráfico 3 apresenta uma classificação das definições dadas pelos autores renomados.

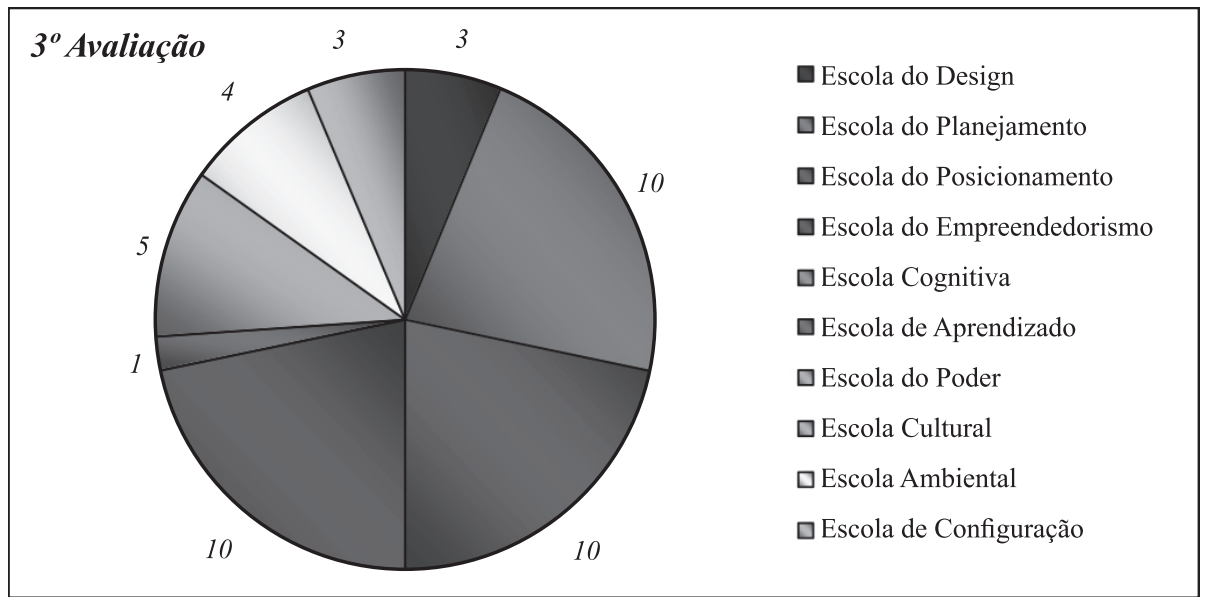

Gráfico 3 - Classificação das definições dos autores consagrados Fonte: dados da pesquisa (2009).

Os resultados são: planejamento, posicionamento e empreendedora, com 21,74\%; poder, 
com 10,87\%; ambiental, com 8,70\%; design e configuração, com $6,52 \%$; e aprendizado, com $2,17 \%$. Não foram citadas as escolas cognitivas - como em nenhuma das vezes anteriores, o que vem a confirmar que esta escola se caracteriza muito mais pela sua potencialidade do que pela sua contribuição, o que vai ao encontro de Mintzberg, Ahlstrand e Lampel (2010) - e cultural. Nota-se novamente uma queda do índice relativo à escola do planejamento (8 p.p. comparado com a classificação anterior), e um pequeno acréscimo do escore alcançado pela escola do posicionamento (pouco mais de 4 p.p.).

Quanto à análise léxica, as 5 palavras mais utilizadas, excluída a palavra estratégia, constam do Quadro 3: profissionais em dois momentos, antes e depois de se submeterem a uma disciplina de estratégia empresarial. Numa segunda etapa, confrontou-se o conhecimento desses profissionais com aqueles apresentados por alguns autores renomados da área de estratégia, os quais estão relacionados no Quadro 1.

Percebeu-se, na primeira avaliação, uma preferência dos alunos pelas escolas prescritivas, com ênfase na escola do planejamento. Esse fato talvez explique a penetração no mercado do artefato planejamento estratégico, proveniente da já referida escola do planejamento.

Já na segunda avaliação, ficou patente a evolução da diversificação conceitual das defini-

\begin{tabular}{|l|c|l|c|l|c|}
\hline \multicolumn{2}{|c|}{$1^{\text {a }}$ Avaliação } & \multicolumn{2}{c|}{$\mathbf{2}^{\text {a }}$ Avaliação } & \multicolumn{2}{c|}{ Definições dos Autores Consagrados } \\
\hline Planejamento/planejar/plano(s) & 34 & Empresa(s) & 17 & Objetivo(s) & 16 \\
\hline Objetivo(s) & 29 & Organização(ões) & 12 & Empresa(s) & 12 \\
\hline Organização(ões) & 23 & Objetivo(s) & 09 & Envolvente(ver) & 08 \\
\hline Atingir/atingimento & 16 & Mercados(s) & 08 & Ação(ões) & 07 \\
\hline Forma(s) & 13 & Competitiva(s) & 06 & Atingir & 07 \\
\hline
\end{tabular}

Quadro 3 - Classificação das definições dos alunos ao final da disciplina

Fonte: dados da pesquisa (2009).

Na primeira avaliação, percebe-se maior participação das palavras planejamento, planejar, plano, objetivo e organização, características da escola do planejamento, o que vem a confirmar a predominância desta escola na primeira avaliação. Já na segunda avaliação, surgem palavras como "mercado" e "competitiva", indicando a presença das escolas do posicionamento e empreendedora. Com relação às definições dos autores consagrados, as palavras mais citadas são "objetivo" e "empresa", o que mostra que os conceitos de estratégia apresentados estão mais focados, muito embora não se distanciem das demais (e.x.: as palavras "objetivo", "atingir" e "empresa" também foram citados nas avaliações dos alunos).

\section{CONSIDERAÇÕES FINAIS}

A presente pesquisa abordou, numa primeira etapa, a comparação do conhecimento de ções apresentadas ao final da disciplina ministrada. Percebe-se, também, que a classificação das definições dos autores não difere tanto daquela apresentada pelos alunos (na segunda avaliação), se aproximando, inclusive, de um ponto de vista muito mais prescritivo do que descritivo.

Como trabalhos futuros, sugere-se $\mathrm{o}$ aprofundamento das análises, inclusive por meio do software Sphinx Léxica-V5.

\section{STRATEGY CONCEPT: PROFESSIONAL PERCEPTION VERSUS CONSECRATED AUTHORS' VISION}

\section{ABSTRACT}

The theme developed in this work is centered on the comparison between tacit knowledge and the theory about what strategy is, in order to observe the evolution or change of thought 
of the research in relation to what some reputed authors expose. Therefore, Corporate Strategy students of an Professional Master Business Administration Course at a public university of Ceará were submitted to an evaluation at the beginning of the course, consisting of an open question, by which they should present their opinions about the significance of the concept of strategy, having as a base readings previously made as well as their professional and personal experiences (tacit knowledge). At the end of that discipline, another evaluation was applied, containing the same open question, in order to assess the level of knowledge acquired in the strategy concepts after the presentation and discussion of texts on the topic at hand. Once in possession of the material collected, a content analysis was carried out, supported by the software Sphinx Lexical-V5 in order to obtain data that would help in the interpretation and understanding of the views expressed by the students. From these data, a comparison between the different times of the collection of testimonies can be established and thus observe the evolution or change of mind of the student during the course. Moreover, there may also be a comparison between the definitions presented and the ones which were exposed by some authors established in the literature (theoretical knowledge), which characterizes them as an exploratory, bibliographical-documental and qualitative research with emphasis on planning.

Keywords: Concept of strategy. Corporate strategy. Strategy.

\section{REFERÊNCIAS}

ANDREWS, K. R. The concept of corporate strategy. Illinois: Dow Jones-Irwin Homewood, 1965.

O que é estratégia. In: MINTZBERG, H.; QUINN, J. B. O processo da estratégia. 3. ed. Porto Alegre: Bookman, 2001. p. 58-64.

ANSOFF, I. Corporate strategy: an analytical approach to business policy for growth and expansion. New York: McGraw-Hill, 1965.

ANSOFF, I; McDONNELL, E. J. Implantando a administração estratégica. 2. ed. São Paulo: Atlas, 1993. p. 590.

CARVALHO, M. M.; LAURINDO, F. J. B. Estratégias para competitividade. São Paulo: Futura, 2003.

CHANDLER, A. Strategy and structure. Cambridge: MIT Press, 1962.

CHRISTENSEN, C. M.; OVERDORF, M. Meeting the Challenge of Disruptive Innovation. Harvard Business Review, United States, v. 78, n. 2, p. 66-76, 2000.

CORDEIRO, J. V. B. de M. Alinhamento estratégico: estudos multicasos em empresas paranaenses de médio porte. 2005. 299 f. Tese (Doutorado em Engenharia de Produção) - Programa de Pós-Graduação em Engenharia de Produção, Universidade Federal de Santa Catarina, Santa Catarina, 2005.

DRANOVE, D.; MARCIANO, S. Estratégia: conceitos, ferramentas e modelos para profissionais. São Paulo: Atlas, 2007.

DRUCKER, Peter F. Administração: tarefas, responsabilidades, práticas. São Paulo: Pioneira, 1975. v. 1.

FREITAS, H. Técnica inovadora para análise de dados qualitativos. In: SBSI-SIMPÓSIO BRASILEIRO DE SISTEMAS DE INFORMAÇÃO, 1., 2004, Porto Alegre. Anais... Porto Alegre: PUCRS, UFRGS, UNISINOS, UCS, 2004. p. 205-212.

FOSTER, R.; KAPLAN, S. Creative Destruction: Why Companies That Are Built to Last Underperform the Market - and How to Successfully Transform Them. New York: Doubleday, 2001.

GONÇALVES, C. A.; DIAS, A. T.; MUNIZ, 
R. M. Análise discriminante das relações entre fatores estratégicos, indústria e desempenho em organizações brasileiras atuantes na indústria manufatureira. Revista de Administração Contemporânea, Curitiba, v. 12, n. 2, p. 287311, abr./jun. 2008.

GONSALVES, E. P. Conversa sobre iniciação à pesquisa científica. Campinas: Alínea, 2007.

KAPLAN, R. S.; NORTON, D. P. A estratégia em ação: balanced scorcard. Rio de Janeiro: Elsevier, 1997.

MARIETTO, M. et al. Teoria do caos: uma contribuição para formação de estratégias. In: EnANPAD, 30., 2006, Salvador. Anais... Salvador: Anpad, 2006. 1 CD-ROM.

MINTZBERG, H.; AHLSTRAND, B.; LAMPEL, J. Safári de estratégia: um roteiro pela selva do planejamento estratégico. Porto Alegre: Bookman, 2010.

POPADIUK, S. Exploration-exploitation de ativos de conhecimento: sobrevivência, paridade ou desempenho superior? In: EnANPAD, 31., 2007, Rio de Janeiro. Anais... Rio de Janeiro: Anpad, 2007. 1 CD-ROM.

PORTER, M. E. Competitive strategy: techniques for analyzing industries and competitors. New York: Free Pess, 1980.

. Estratégia competitiva: técnicas para análise de indústrias e da concorrência. 7. ed. Rio de Janeiro: Elsevier, 1986.

Vantagem competitiva: criando e sustentando um desempenho superior. 11. ed. Rio de Janeiro: Campus, 1989.

SELZNICK, P. Leadership in administration: a sociological interpretation. Evanston: Row Peterson, 1957.

TOSCANI, C. V.; STEINER NETO, P. J. A formulação de estratégias empresariais em ambientes com alianças estratégicas: o caso do centro vivo sob a ótica de Whittington. In: EnANPAD, 31., 2007, Rio de Janeiro. Anais... Rio de Janeiro: Anpad, 2007. 1 CD-ROM.

WERNERFELT, B. A Resource-Based View of the Firm. Strategic Management Journal, United Kingdom, v. 5, n. 2, p. 171-180, Apr./ June, 1984.

ZILBER, M. A. et al. Estratégia competitiva: um estudo da indústria do alumínio. In: EnANPAD, 30., 2006, Salvador. Anais... Salvador: Anpad, 2006. 1 CD-ROM. 